\title{
Nicotinic Receptors in the Habenulo-Interpeduncular System Are Necessary for Nicotine Withdrawal in Mice
}

\author{
Ramiro Salas, ${ }^{1 \star}$ Renea Sturm, ${ }^{1 \star}$ Jim Boulter, ${ }^{2}$ and Mariella De Biasi ${ }^{1}$ \\ ${ }^{1}$ Department of Neuroscience, Baylor College of Medicine, Houston, Texas 77030, and 2Department of Psychiatry and Biobehavioral Sciences, Hatos \\ Research Center for Neuropharmacology, Brain Research and Molecular Biology Institutes, University of California, Los Angeles, Los Angeles, California \\ 90095
}

In humans, tobacco withdrawal produces symptoms that contribute to the difficulty associated with smoking cessation. Nicotine withdrawal symptoms can also be observed in rodents. A major standing question is which nicotinic receptor subtypes and which areas of the brain are necessary for nicotine withdrawal to occur. Using knock-out mice, we previously showed that the $\beta 4$, but not the $\beta 2$ subunit of nicotinic acetylcholine receptors, is necessary for the somatic manifestations of nicotine withdrawal. Since the $\beta 4$ subunit is highly expressed in the medial habenula, we focused our studies on the medial habenula and its primary target, the interpeduncular nucleus. In particular, we studied nicotine withdrawal in mice lacking the $\alpha 2$ or the $\alpha 5$ nicotinic receptor subunits, which are highly expressed in the interpeduncular nucleus. We precipitated withdrawal by systemically injecting the nicotinic antagonist mecamylamine in mice chronically treated with nicotine. Both the $\alpha 2$ and the $\alpha 5$ null mutations abolished the somatic manifestations of nicotine withdrawal. In addition, in wild-type mice chronically treated with nicotine, mecamylamine precipitated withdrawal when microinjected into the habenula or the interpeduncular nucleus, but not into the cortex, ventral tegmental area or hippocampus. Our results demonstrate a major role for the habenulo-interpeduncular system and the nicotinic receptor subunits expressed therein, in nicotine withdrawal symptoms. Our data suggest that the efforts to develop new smoking cessation therapies should concentrate on these areas and receptor types.

\section{Introduction}

The withdrawal symptoms that appear upon smoking cessation are one of the major factors precluding people from successfully quitting tobacco use (West et al., 1989). In fact, nicotine withdrawal and cravings might have a role in tobacco use relapse, even long after the initial period of withdrawal symptoms (usually $\sim 2$ weeks) is over (Allen et al., 2008). In humans, symptoms of nicotine withdrawal include, among others, anxiety, irritability, restlessness, bradycardia, and weight gain (Hughes and Hatsukami, 1986; De Biasi and Salas, 2008). Mice display both somatic (e.g., shaking, paw tremors or scratching) and affective signs of withdrawal (e.g., increased anxiety-like behavior in the elevated plus maze or increased threshold for intracranial self-stimulation). Those signs can be measured with a number of different behavioral tests (Damaj et al., 2003; De Biasi and Salas, 2008).

The mechanisms underlying nicotine withdrawal are still poorly understood. In mice, nicotine withdrawal has been precipitated with antagonists with preferential effects on either $\alpha 3 \beta 4$-, $\alpha 4 \beta 2$ - or $\alpha 7$-containing nicotinic acetylcholine receptors

Received 0ct. 13, 2008; revised Dec. 22, 2008; accepted Jan. 10, 2009.

This work was supported by the National Institute on Drug Abuse (Grant DA017173 to M.D.B.), Tobacco-Related Disease Research Program (Grant 10RT-0136 to J.B.), and University of California, Los Angeles Stein Oppenheimer Endowment Award (J.B.). We thank Tetyana Aleksenko for excellent technical support.

*R. Salas and R. Sturm contributed equally to this work.

Correspondence should be addressed to Mariella De Biasi, Department of Neuroscience, Baylor College of Medicine, Houston, TX 77030. E-mail debiasi@bcm.tmc.edu.

D01:10.1523/JNEUROSCI.4934-08.2009

Copyright $\odot 2009$ Society for Neuroscience $\quad$ 0270-6474/09/293014-05\$15.00/0
(nAChRs) (Damaj et al., 2003; De Biasi and Salas, 2008). We have shown, however, that the nAChR antagonist methyllicaconitine (MLA), at concentrations previously thought to be $\alpha 7$-specific, was able to precipitate nicotine withdrawal in $\alpha 7-/-$ mice (Salas et al., 2007). This indicates that the nAChR antagonists available may not be as specific as previously believed and genetic approaches may render more accurate results. To that end, we previously showed that the $\beta 4$, but not the $\beta 2 \mathrm{nAChR}$ subunit, is a critical mediator of withdrawal in mice (Salas et al., 2004). In addition, mice null for the $\alpha 7 \mathrm{nAChR}$ subunit showed an intermediate phenotype, as if this subunit contributes to, but is not necessary for, nicotine withdrawal (Salas et al., 2007). Previously, systemic MLA had been shown to precipitate the somatic signs of nicotine withdrawal in mice (Damaj et al., 2003) but not in the rat (Markou and Paterson, 2001). Central $\alpha 7 \mathrm{nAChR}$ were also shown to be involved in the affective signs of withdrawal (Nomikos et al., 1999). Therefore, the $\alpha 7$ subunit is likely involved in some aspects of nicotine withdrawal.

Given that the $\beta 4 \mathrm{nAChR}$ subunit is highly expressed in the medial aspect of the habenula ( $\mathrm{MHb})$ and in the interpeduncular nucleus (IPN) (Salas et al., 2004), we studied whether nicotinic activity in the $\mathrm{Hb}-\mathrm{IPN}$ axis is responsible for nicotine withdrawal in mice. $\mathrm{Hb}$ and IPN are two small nuclei connected by an axon bundle, the fasciculus retroflexus. In rodents, the Hb-IPN axis has been implicated in a variety of brain functions and behaviors, including nociception, learning and memory, motor activity, sexual and maternal behavior, stress, anxiety, depression, reward, sleep, eating and drinking behavior (Klemm, 2004). 
To investigate the role of the MHb and IPN in nicotine withdrawal, we studied mice null for two subunits highly expressed in the IPN, namely $\alpha 2$ and $\alpha 5$. In addition, the mechanisms of withdrawal were investigated by intracerebral microinjections of mecamylamine into the MHb and IPN and control brain areas of wild-type mice chronically treated with nicotine.

\section{Materials and Methods \\ Animals}

We studied two to 6-month-old C57BL/6J mice and $\alpha 2$ and $\alpha 5$ mutant mice with their littermate wild-type controls. $\alpha 2$ and $\alpha 5$ mutant mice were a minimum of generation N8 to N10 inbred into a C57BL/6J background. Weaning was performed $21 \mathrm{~d}$ after birth, and littermates of the same sex were housed in cages containing a maximum of five animals. Male and female mice were housed in polycarbonate cages under a $12 \mathrm{~h}$ light/dark cycle, in a temperature controlled room $\left(24 \pm 2^{\circ} \mathrm{C}\right.$, relative humidity $55 \pm 10 \%$ ) with access to food and water ad libitum. All surgical and experimental procedures were performed during the light phase, between 7:00 A.M. and 7:00 P.M. The experimenters remained blind to genotype and treatment until final data analysis. Mice were regenotyped after the experiments. All procedures were approved by the Baylor College of Medicine Animal Care and Use Committee and followed the guidelines for animal intramural research from the National Institute of Health.

\section{Surgical procedure}

Before surgical procedures, animals were anesthetized by intraperitoneal injection of a combination anesthetic (ketamine $100 \mathrm{mg} / \mathrm{ml}$, xylazine 20 $\mathrm{mg} / \mathrm{ml}$, acepromazine $10 \mathrm{mg} / \mathrm{ml}$ ) at a dosage of $1.5-2 \mathrm{ml} / \mathrm{kg}$. Lidocaine $\mathrm{HCl}(2 \%)$ was applied locally before incision and trepanation. The tip of the cannula guide (internal 33G, Plastics One) was positioned relative to bregma, using a stereotaxic apparatus (Stoelting). The coordinates (Paxinos and Franklin, 1997) used for cannula placement were as follows: $\mathrm{MHb}$, anterior/posterior (AP) -0.17 or -0.18 medial/lateral (ML) \pm 0.2 , dorso/ventral (DV) -0.27 ; IPN, $20^{\circ}$ angle, $\mathrm{AP}-0.36, \mathrm{ML}+0.17$, $\mathrm{DV}-0.49$; cortical control, AP $-0.2, \mathrm{ML} \pm 0.2$, DV -0.1 ; ventral tegmental area (VTA) control, $10^{\circ}$ angle, AP 0.36, ML 0.16-0.2, DV 0.46, or $5^{\circ}$ angle, AP 0.36, ML 0.12-0.16, DV 0.44. The incisor bar was level with the interaural line. Two holes were drilled for placement of small brass screws and the cannula base was secured with carboxylate cement (Durelon, $3 \mathrm{M}$ ). Mice were allowed to recover from surgery for a minimum of $3 \mathrm{~d}$ before microinjection and withdrawal testing.

\section{Nicotine treatment}

Mice received nicotine treatment by one of two modalities: either via subcutaneously implanted, constant release, osmotic minipumps (see Figs. $1 A, 2,3$ ) or via nicotine in the drinking water (see Fig. $1 B$ ). These two methods allow nicotine delivery either in a constant, highly regulated amount (minipumps), or in a more variable, pulsatile manner (nicotine in the water) to better mimic nicotine intake in human smokers. Both delivery methods were used in the $\alpha 5$ mutants to confirm that the phenotypes observed were not an artifact associated with one of the methods. Mice treated with osmotic minipumps were subcutaneously implanted with Alzet pumps model 1004 ( $14 \mathrm{~d}$, flow rate $0.25 \mu \mathrm{l} / \mathrm{h}$ ) according to manufacturer's instructions. Pumps were filled with either saline or nicotine tartrate in saline to deliver a $24 \mathrm{mg} / \mathrm{Kg} / \mathrm{d}$ dose of nicotine (as free base) for $13 \mathrm{~d}$. Mice treated with nicotine in the drinking water received 6 weeks of treatment before withdrawal testing. The concentrations of nicotine in the water increased from $100 \mu \mathrm{g} / \mathrm{ml}$ of nicotine tartrate (measured as free base) the first week to $300 \mu \mathrm{g} / \mathrm{ml}$ the second week, followed by a final concentration of $500 \mu \mathrm{g} / \mathrm{ml}$ for the duration of the final 4 -week period (Salmon et al., 2004). A similar regimen has been demonstrated to produce behavioral tolerance (Sparks and Pauly, 1999) and cause upregulation of brain nAChRs (Sparks and Pauly, 1999). To minimize hypodypsia due to taste aversion, $2 \%$ saccharine was added to the water of both experimental and control groups.

\section{Nicotine withdrawal}

Withdrawal precipitated by systemic mecamylamine. After $13 \mathrm{~d}$ of chronic treatment via minipumps or 6 weeks of nicotine in the drinking water,
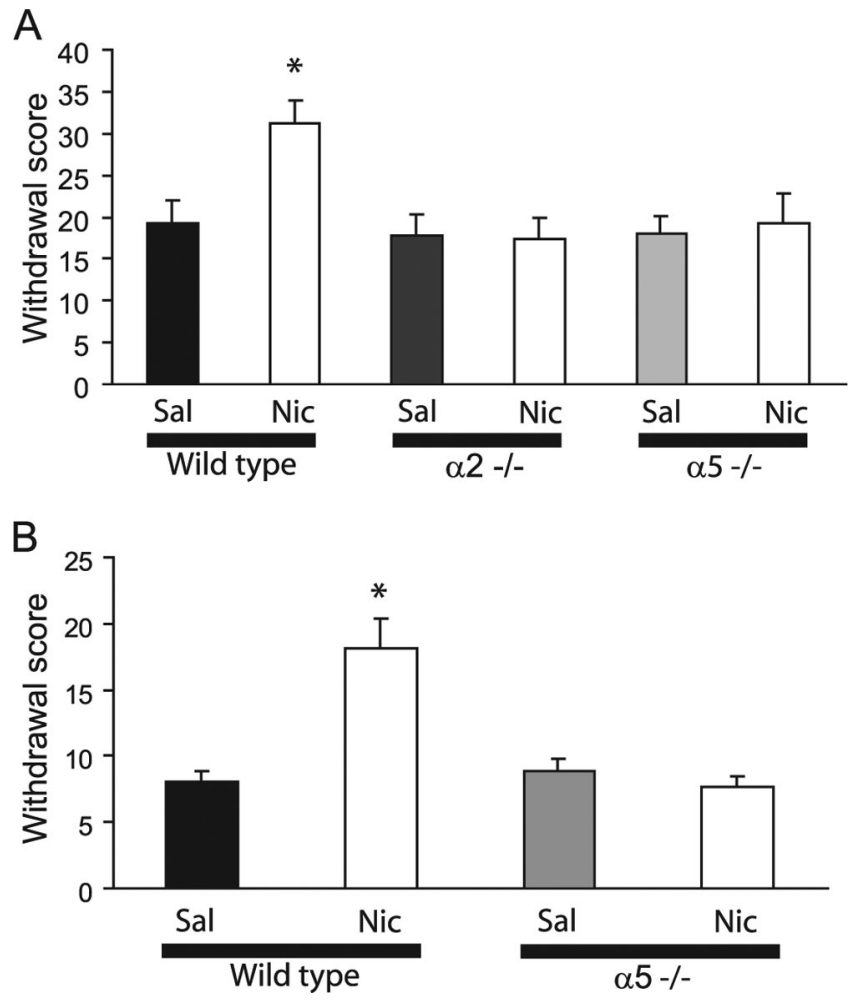

Figure 1. Mecamylamine-induced somatic signs of withdrawal in wild-type, $\alpha 2-/-$ and $\alpha 5-/-$ mice. $A$, Mice receiving nicotine via osmotic minipumps. Total nicotine withdrawal signs in control mice $(+/+)$ treated with saline ( $n=10$, black bars) or nicotine ( $n=16$, white bars), $\alpha 2-1-$ mice treated with saline ( $n=8$, dark gray bars) or nicotine ( $n=12$, white bars), and $\alpha 5-/-$ mice treated with saline ( $n=9$, light gray bars) or nicotine ( $n=13$, white bars) during the 20 min immediately after mecamylamine injection. $\boldsymbol{B}$, Mice treated with nicotine in the drinking water. Total nicotine withdrawal signs over $10 \mathrm{~min}$ in control mice $(+/+)$ treated with saline $(n=$ 17 , black bars) or nicotine ( $n=8$, white bars), and $\alpha 5-1-$ mice treated with saline ( $n=8$, dark gray bars) or nicotine ( $n=13$, white bars). ${ }^{*} p<0.05$ versus $+/+$ saline (ANOVA and LSD post hoc comparisons). Error bars represent SEM.

mice were intraperitoneally injected with $3 \mathrm{mg} / \mathrm{Kg}$ of racemic mecamylamine, and immediately put back into their cage. Withdrawal signs were recorded by an experimenter blind to treatment and genotype, for $20 \mathrm{~min}$ (nicotine in osmotic minipump) or $10 \mathrm{~min}$ (nicotine in drinking water). A pilot study conducted on drug-naive C57BL/6J mice indicated that $3 \mathrm{mg} / \mathrm{Kg}$ of mecamylamine alone does not increase withdrawal signs under our experimental conditions (data not shown).

Withdrawal precipitated by mecamylamine microinjection. Mice previously implanted with cannula guides, as described above, were tested using a similar behavioral withdrawal paradigm. Microinjections were made via a stainless-steel injection cannula inserted into the cannula guide. The injection cannula was attached to a $2.5 \mu \mathrm{l}$ Hamilton syringe by polyethylene tubing (PE-20). The injection of $0.5-1 \mu \mathrm{l}$ saline was followed by removal of the injection cannula after 1-2 min and return of the mouse to its home cage. After a 15-min rest period, the mouse was observed for somatic signs for $10 \mathrm{~min}$ to establish baseline scores. Before the second injection, the mouse remained in the home cage for $1 \mathrm{~h}$ with access to the respective drinking solution. Subsequently, a second microinjection of $0.5 \mu \mathrm{l}$ of $2 \mu \mathrm{g} / \mu \mathrm{l}$ mecamylamine solution with $2 \%$ methylene blue was delivered, again followed by a 15 -min rest period and a 10-min scoring period. (-)-Nicotine tartrate and mecamylamine were purchased from Sigma and dissolved in PBS.

For all tests of withdrawal, the following primary parameters representative of somatic signs of withdrawal were monitored, with each event receiving a score of one point: grooming, scratching, chewing and shaking. Secondary parameters, scored as no more than one point per minute during which each the behavior was observed, were as follows: cage scratching, head nodding, and jumping. 


\section{Tissue preparation}

Immediately after completion of each microinjection experiment, mice were decapitated and their brains frozen in $-20^{\circ} \mathrm{C}$ isopentane. Fresh frozen brains were cryostat cut $(25 \mu \mathrm{m})$, slidemounted, and the injection site observed using the methylene blue stain as a marker of cannula placement. Finally, a light hematoxylin counterstaining was performed on some brains and the tissue was dehydrated to assist in verifying the course of the cannula guide track.

\section{Data analysis}

Data on somatic signs of withdrawal in mutant mice were analyzed by one-way ANOVA followed by Fisher's Least Significant Difference (LSD) post hoc comparisons. Data on microinjections was analyzed by two-way ANOVA (acute drug $\times$ injection site) or three-way ANOVA (chronic treatment $X$ acute drug $X$ injection site, used only for MHb and IPN), followed by Newman-Keuls post hoc comparisons.

\section{Results}

$\alpha 2-/-$ and $\alpha 5-/-$ mice show

decreased somatic signs of

nicotine withdrawal

During the 20 min of observation after intraperitoneal mecamylamine injection, wild-type mice that were chronically treated with nicotine exhibited significantly more somatic signs of withdrawal than saline-treated mice or $\alpha 2-/-$ and $\alpha 5-/-$ nicotine-treated mice (Fig. 1A). On ANOVA, there was an effect of genotype $\left(F_{(2,62)}=4.5, p<0.01\right)$ and an interaction between genotype and treatment $\left(F_{(2,62)}=6.5, p<0.005\right)$. On LSD post hoc test, the group of wild-type mice treated with nicotine was statistically different to all other groups, while no other comparison was statistically significantly different (Fig. $1 A$ ).

To verify the robustness of the phenotype, we repeated the withdrawal experiment on $\alpha 5+/+$ and $\alpha 5-/-$ mice treated with nicotine in the drinking water instead of osmotic pump. As seen in Figure $2 B$, nicotine-treated wild-type mice showed obvious nicotine withdrawal, while $\alpha 5-/-$ mice (both saline and nicotine treated) were comparable with saline-treated wild-type mice. ANOVA revealed an effect of genotype $\left(F_{(1,42)}=10.7, p<0.005\right)$, an effect of treatment $\left(F_{(1,42)}=8.6, p<0.01\right)$, and an interaction $\left(F_{(1,42)}=14.3, p<0.0005\right)$. On LSD post hoc analysis, the nicotinetreated wild-type group was statistically different to all other groups. No other comparison was statistically different (Fig. $1 B$ ).

\section{Mecamylamine microinjection to the MHb or IPN, but not the cortex, hippocampus, or VTA, precipitates somatic signs of nicotine withdrawal in wild-type mice}

In wild-type mice chronically treated with nicotine, withdrawal symptoms were recorded for 10-min scoring periods before and after mecamylamine microinjection into either the habenula, the cortex, the hippocampus, the VTA or the IPN. In those mice, mecamylamine precipitated a statistically equivalent increase in somatic signs of nicotine withdrawal when injected into the $\mathrm{Hb}$ or the IPN, but not when injected into the cortex, hippocampus, or VTA (Figs. 2, 3). The scores of premecamylamine and postmecamylamine injection in chronic saline-treated and preinjection in nicotine-treated mice showed no statistical difference. Cortical, hippocampus, and VTA microinjections in nicotine-treated mice produced preinjection and postinjection scores similar to saline-treated and preinjection baseline scores. Data were analyzed with ANOVA using two variables: location (cortex, VTA, Hb, IPN, hippocampus) and drug (saline, mecamylamine, repeated measure). There was an effect of location $\left(F_{(4,27)}=6.6, p<\right.$ $0.005)$, an effect of drug $\left(F_{(1,27)}=26.3, p<0.00005\right)$, and an interaction between location and drug $\left(F_{(4,27)}=10.7, p<\right.$ $0.00005)$. For $\mathrm{Hb}$ and IPN, we performed ANOVA using three variables: location ( $\mathrm{Hb}, \mathrm{IPN})$, treatment (saline, nicotine) and drug (saline, mecamylamine, repeated measure). There was an effect of treatment $\left(F_{(1,18)}=5.3, p<0.05\right)$, an effect of drug $\left(F_{(1,18)}=26.8, p<0.0001\right)$, and an interaction between treatment and drug $\left(F_{(1,18)}=17.1, p<0.001\right)$. On Newman-Keuls post hoc comparisons, the only significant differences found were that the IPN/nicotine/mecamylamine and the Hb/nicotine/mecamylamine groups were different from all other groups, but not different from each other (Figs. 2, 3). For visual purposes, the $\mathrm{Hb}$ data are shown together with the cortex and hippocampus controls (Fig. 2) and the IPN data together with the VTA controls (Fig. 3).

\section{Discussion}

We have shown that the lack of either the $\alpha 2$ or $\alpha 5$ nAChRs subunits is sufficient to decrease the somatic signs of mecamylamine-induced nicotine withdrawal to the baseline levels exhibited by saline-treated mice. We have previously demonstrated that lack of the $\beta 4$ subunit produces a similar phenotype (Salas et al., 2004). While no data has been published showing an effect of the $\alpha 2$ null mutation on nicotine's effects, the $\alpha 5$ subunit has already been implicated in the effects of nicotine in mice. We previously demonstrated that $\alpha 5-/-$ mice have decreased sensitivity to the acute effects of nicotine both at high doses (seizures) and moderate doses (hypolocomotion) (Salas et al., 2003). 

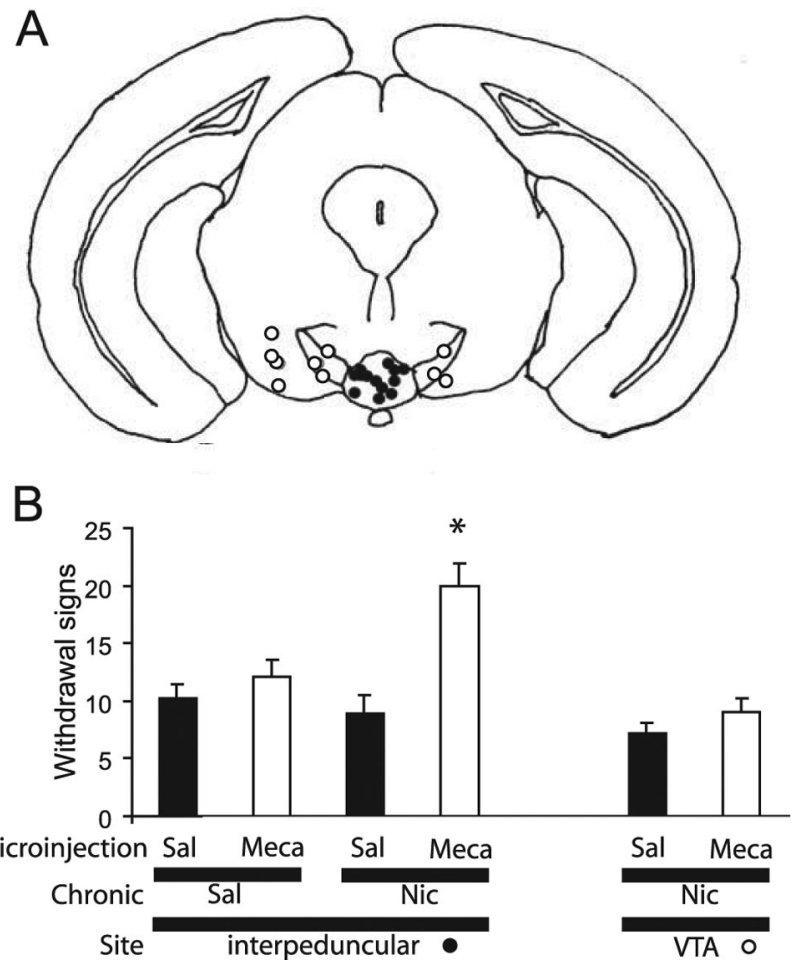

Figure 3. Nicotine withdrawal signs in wild-type mice after microinjection of mecamylamine into the IPN and VTA. $\boldsymbol{A}$, Schematic of injection sites. $\boldsymbol{B}$, Withdrawal signs after microinjection of saline (Sal, black bars) and $1 \mu \mathrm{g}$ of mecamylamine (Meca, white bars) into the IPN $\left(N=6,7\right.$, respectively) or VTA $(N=10) .{ }^{*} p<0.05$ Sal versus Meca for same site and same chronic treatment (Neuman-Keuls post hoc comparisons). Error bars represent SEM.

The $\alpha 5$ subunit has also been linked to somatic (but not affective) signs of nicotine withdrawal in mice (Jackson et al., 2008).

The $\alpha 5$ and $\beta 4$ subunits are in a gene cluster that also contains the $\alpha 3$ subunit (Boulter et al., 1990). Data from genetic screens in humans support the hypothesis that this genetic cluster influences nicotine addiction behavior. For example, in a recent association analysis of 306,207 single nucleotide polymorphisms (SNPs) studied in a sample of 15,771 smokers, the primary allele correlation with nicotine dependence was a SNP within CHRNA3 (the $\alpha 3 \mathrm{nAChR}$ subunit) which is in a linkage disequilibrium block also containing the $\alpha 5$ and $\beta 4 \mathrm{nAChR}$ subunit genes (Thorgeirsson et al., 2008). Other recent reports showed an involvement of variants in those three $\mathrm{nAChR}$ subunits as risk factors for heavy smoking (Berrettini et al., 2008) and lung cancer susceptibility (Amos et al., 2008; Hung et al., 2008). Therefore, several studies suggest that the gene cluster containing the $\alpha 3, \alpha 5$ and $\beta 4$ subunits is important for nicotine addiction.

The three nAChR subunits that have an effect on nicotine withdrawal in mice $(\alpha 2, \alpha 5$, and $\beta 4)$ have in common an overlapping expression pattern: the $\beta 4$ subunit is highly expressed in the MHb and is present in the IPN (Salas et al., 2004), the $\alpha 5$ subunit is present in the MHb (Broide et al., 2002) and is highly expressed in the IPN (Wada et al., 1990), and the $\alpha 2$ subunit is highly expressed in the IPN (Ishii et al., 2005). Although these subunits are also expressed in other areas, no other brain system contains an expression pattern consistent with shared functions. In addition, the $\mathrm{Hb}$ and the IPN are connected through the fasciculus retroflexus, suggesting shared functions. The habenulointerpeduncular system has been implicated in several behaviors such as anxiety-like, feeding and sleeping patterns, stress, aggression, sexual and maternal behavior, among others (Klemm,
2004). Interestingly, the $\mathrm{Hb}$ has also been shown to modulate dopaminergic activity in striatal areas (Matsumoto and Hikosaka, 2007), which are known to be important for the effects of drugs of addiction, including nicotine (Hyman et al., 2006).

It was previously established that systemic mecamylamine precipitates withdrawal in nicotine-treated rodents (Malin et al., 1994). To address the hypothesis that the MHb-IPN axis is a mediator of nicotine withdrawal, we implanted cannulae into specific brain regions of nicotine-treated mice, using microinjections of mecamylamine to precipitate withdrawal. As hypothesized, we found that injection of mecamylamine into the $\mathrm{Hb}$ or the IPN, but not in several other brain areas, is sufficient to precipitate withdrawal in mice chronically treated with nicotine. It must be noted that whether nicotine withdrawal is centrally or peripherally mediated has been highly controversial. Watkins et al. (2000) concluded that in rats, somatic signs of withdrawal have an important peripheral component, while withdrawalinduced elevations in reward thresholds in self intracranial stimulation were centrally mediated. It was also reported that peripheral nicotinic antagonists can precipitate withdrawal in dependent rats (Hildebrand et al., 1997). In contrast, Malin et al. (1997) reported that central, but not peripheral hexamethonium, precipitates somatic signs of withdrawal in rats. Our data suggests that central effects are necessary and sufficient for the somatic effects of withdrawal. However, we cannot rule out the possibility that peripheral effects also contribute to withdrawal.

We hypothesize that chronic nicotine treatment produces neuroadaptations at the level of the $\mathrm{Hb}-\mathrm{IPN}$ axis. When nicotine is present in an addicted brain, nearly continuous activation of $\beta 4-, \alpha 2$ - and/or $\alpha 5$-containing channels in the MHb-IPN axis may be responsible for maintaining modulated neural activity. In our withdrawal model, mecamylamine is added to critical areas to precipitate withdrawal. We suggest that the instantaneous decrease in $\mathrm{nAChR}$ activation in this area, in a brain that has already undergone nicotine-induced neuroadaptations, is what precipitates withdrawal symptoms. In mice that lack the necessary subunits for neuroadaptation to occur, nicotine withdrawal cannot be precipitated. In contrast, mice lacking the $\beta 2$ subunit, which is necessary for nicotine self-administration and reward (Picciotto et al., 1998; Maskos et al., 2005), demonstrated normal mecamylamine-precipitated nicotine withdrawal (Salas et al., 2004). The segregation of the roles of these two types of nAChRs, $\beta 2$-containing $\mathrm{nAChRs}$ in the VTA-striatum axis as important for self-administration (Maskos et al., 2005), and $\beta 4 / \alpha 5 / \alpha 2$ containing $\mathrm{nAChR}$ in the $\mathrm{Hb}-\mathrm{IPN}$ axis as important for nicotine withdrawal, is a critical piece of data to understand nicotine addiction at the molecular and brain systems level. Because the $\mathrm{Hb}-\mathrm{IPN}$ axis is part of a bigger circuit that includes reward areas such as the VTA and the striatum, other brain areas and other nAChR subtypes could be affected by Hb/IPN activity.

In conclusion, we have shown that the $\alpha 2$ and $\alpha 5 \mathrm{nAChRs}$ subunits are necessary mediators of nicotine withdrawal in mice. Importantly, we also demonstrated that blockade of nicotinic activity in the Hb-IPN axis, a brain region where these subunits are expressed, precipitates nicotine withdrawal in mice that have been chronically treated with nicotine. Both withdrawal and reward are likely to be important in mediating nicotine addiction. We showed that somatic withdrawal is mediated mainly by the nAChRs in the MHb and IPN. To develop novel and increasingly effective drug therapies for smoking cessation, it will be necessary to understand the specific roles of each $\mathrm{nAChR}$ subunit in normal physiology as well as in disease. Our data point to certain nAChR types, in a very specific region of the brain, as mediators of nico- 
tine withdrawal, and therefore as potentially relevant therapeutic targets.

\section{References}

Allen SS, Bade T, Hatsukami D, Center B (2008) Craving, withdrawal, and smoking urges on days immediately prior to smoking relapse. Nicotine Tob Res 10:35-45.

Amos CI, Wu X, Broderick P, Gorlov IP, Gu J, Eisen T, Dong Q, Zhang Q, Gu X, Vijayakrishnan J, Sullivan K, Matakidou A, Wang Y, Mills G, Doheny K, Tsai YY, Chen WV, Shete S, Spitz MR, Houlston RS (2008) Genomewide association scan of tag SNPs identifies a susceptibility locus for lung cancer at 15q25.1. Nat Genet 40:616-622.

Berrettini W, Yuan X, Tozzi F, Song K, Francks C, Chilcoat H, Waterworth D, Muglia P, Mooser V (2008) Alpha-5/alpha-3 nicotinic receptor subunit alleles increase risk for heavy smoking. Mol Psychiatry 13:368-373.

Boulter J, O'Shea-Greenfield A, Duvoisin RM, Connolly JG, Wada E, Jensen A, Gardner PD, Ballivet M, Deneris ES, McKinnon D, Heinemann S, Patrick J (1990) Alpha 3, alpha 5, and beta 4: three members of the rat neuronal nicotinic acetylcholine receptor-related gene family form a gene cluster. J Biol Chem 265:4472-4482.

Broide RS, Salas R, Ji D, Paylor R, Patrick JW, Dani JA, De Biasi M (2002) Increased sensitivity to nicotine-induced seizures in mice expressing the L250T alpha7 nicotinic acetylcholine receptor mutation. Mol Pharmacol 61:695-705.

Damaj IM, Kao W, Martin BR (2003) Characterization of spontaneous and precipitated nicotine withdrawal in the mouse. J Pharmacol Exp Ther 307:526-534.

De Biasi M, Salas R (2008) Influence of neuronal nicotinic receptors over nicotine addiction and withdrawal. Exp Biol Med (Maywood) 233:917-929.

Hildebrand BE, Nomikos GG, Bondjers C, Nisell M, Svensson TH (1997) Behavioral manifestations of the nicotine abstinence syndrome in the rat: peripheral versus central mechanisms. Psychopharmacology (Berl) 129:348-356.

Hughes JR, Hatsukami D (1986) Signs and symptoms of tobacco withdrawal. Arch Gen Psychiatry 43:289-294.

Hung RJ, McKay JD, Gaborieau V, Boffetta P, Hashibe M, Zaridze D, Mukeria A, Szeszenia-Dabrowska N, Lissowska J, Rudnai P, Fabianova E, Mates D, Bencko V, Foretova L, Janout V, Chen C, Goodman G, Field JK, Liloglou $\mathrm{T}$, Xinarianos G, et al. (2008) A susceptibility locus for lung cancer maps to nicotinic acetylcholine receptor subunit genes on $15 \mathrm{q} 25$. Nature 452:633-637.

Hyman SE, Malenka RC, Nestler EJ (2006) Neural mechanisms of addiction: the role of reward-related learning and memory. Annu Rev Neurosci 29:565-598.

Ishii K, Wong JK, Sumikawa K (2005) Comparison of alpha2 nicotinic acetylcholine receptor subunit mRNA expression in the central nervous system of rats and mice. J Comp Neurol 493:241-260.

Jackson KJ, Martin BR, Changeux JP, Damaj MI (2008) Differential role of nicotinic acetylcholine receptor subunits in physical and affective nicotine withdrawal signs. J Pharmacol Exp Ther 325:302-312.

Klemm WR (2004) Habenular and interpeduncularis nuclei: shared components in multiple-function networks. Med Sci Monit 10:RA261-RA273.

Malin DH, Lake JR, Carter VA, Cunningham JS, Hebert KM, Conrad DL, Wilson OB (1994) The nicotinic antagonist mecamylamine precipitates nicotine abstinence syndrome in the rat. Psychopharmacology 115:180-184.

Malin DH, Lake JR, Schopen CK, Kirk JW, Sailer EE, Lawless BA, Upchurch TP, Shenoi M, Rajan N (1997) Nicotine abstinence syndrome precipitated by central but not peripheral hexamethonium. Pharmacol Biochem Behav 58:695-699.

Markou A, Paterson NE (2001) The nicotinic antagonist methyllycaconitine has differential effects on nicotine self-administration and nicotine withdrawal in the rat. Nicotine Tob Res 3:361-373.

Maskos U, Molles BE, Pons S, Besson M, Guiard BP, Guilloux JP, Evrard A, Cazala P, Cormier A, Mameli-Engvall M, Dufour N, Cloëz-Tayarani I, Bemelmans AP, Mallet J, Gardier AM, David V, Faure P, Granon S, Changeux JP (2005) Nicotine reinforcement and cognition restored by targeted expression of nicotinic receptors. Nature 436:103-107.

Matsumoto M, Hikosaka O (2007) Lateral habenula as a source of negative reward signals in dopamine neurons. Nature 447:1111-1115.

Nomikos GG, Hildebrand BE, Panagis G, Svensson TH (1999) Nicotine withdrawal in the rat: role of alpha7 nicotinic receptors in the ventral tegmental area. Neuroreport 10:697-702.

Paxinos G, Franklin K (1997) The mouse brain in stereotaxic coordinates. San Diego: Academic.

Picciotto MR, Zoli M, Rimondini R, Léna C, Marubio LM, Pich EM, Fuxe K, Changeux JP (1998) Acetylcholine receptors containing the beta2 subunit are involved in the reinforcing properties of nicotine. Nature 391:173-177.

Salas R, Orr-Urtreger A, Broide RS, Beaudet A, Paylor R, De Biasi M (2003) The nicotinic acetylcholine receptor subunit alpha 5 mediates acute effects of nicotine in vivo. Mol Pharmacol 63:1059-1066.

Salas R, Pieri F, De Biasi M (2004) Decreased signs of nicotine withdrawal in mice null for the $\beta 4$ nicotinic acetylcholine receptor subunit. J Neurosci 24:10035-10039.

Salas R, Main A, Gangitano D, De Biasi M (2007) Decreased withdrawal symptoms but normal tolerance to nicotine in mice null for the alpha7 nicotinic acetylcholine receptor subunit. Neuropharmacology 53:863-869.

Salmon AM, Evrard A, Damaj I, Changeux JP (2004) Reduction of withdrawal signs after chronic nicotine exposure of alpha-calcitonin generelated peptide knock-out mice. Neurosci Lett 360:73-76.

Sparks JA, Pauly JR (1999) Effects of continuous oral nicotine administration on brain nicotinic receptors and responsiveness to nicotine in C57Bl/6 mice. Psychopharmacology (Berl) 141:145-153.

Thorgeirsson TE, Geller F, Sulem P, Rafnar T, Wiste A, Magnusson KP, Manolescu A, Thorleifsson G, Stefansson H, Ingason A, Stacey SN, Bergthorsson JT, Thorlacius S, Gudmundsson J, Jonsson T, Jakobsdottir M, Saemundsdottir J, Olafsdottir O, Gudmundsson LJ, Bjornsdottir G, et al. (2008) A variant associated with nicotine dependence, lung cancer and peripheral arterial disease. Nature 452:638-642.

Wada E, McKinnon D, Heinemann S, Patrick J, Swanson LW (1990) The distribution of mRNA encoded by a new member of the neuronal nicotinic acetylcholine receptor gene family (alpha 5 ) in the rat central nervous system. Brain Res 526:45-53.

Watkins SS, Stinus L, Koob GF, Markou A (2000) Reward and somatic changes during precipitated nicotine withdrawal in rats: centrally and peripherally mediated effects. J Pharmacol Exp Ther 292:1053-1064.

West RJ, Hajek P, Belcher M (1989) Severity of withdrawal symptoms as a predictor of outcome of an attempt to quit smoking. Psychological Medicine 19:981-985. 